\title{
Flusser, o profeta invertido: a crítica à sociedade de consumo e ao aparelho da ditadura militar em correspondência de Vilém Flusser e José Bueno
}

\section{Tiago da Mota e Silva}

Doutorando; Faculdade Cásper Líbero, São Paulo, SP, Brasil.

tmsilva@casperlibero.edu.br

Norval Baitello Junior

Doutor; Pontificia Universidade Católica de São Paulo, SP, Brasil. norvalbaitello@pucsp.br

\section{Resumo}

O presente artigo seleciona e analisa cartas na troca de correspondências entre Vilém Flusser e José Bueno preservadas no Arquivo Vilém Flusser São Paulo. A pesquisa se debruçou em ler a correspondência trocada desde 29 de maio de 1971 a 10 de julho de 1975 - o que corresponde a 30 cartas, das quais 15 são diretamente citadas neste artigo. Entendeu-se que as cartas selecionadas iniciam e concluem um determinado eixo temático discutido entre eles, justamente sobre economia e política internacional e a situação do Brasil no cenário global da época. Por meio da pesquisa neste arquivo, descobriram-se algumas modulações de como Flusser discutia eventos que lhe eram contemporâneos, como a crise do petróleo de 1973, o caso Watergate e principalmente a ditadura militar brasileira. As cartas demonstram também o interesse de Flusser pela emergente futurologia, em momentos em que o filósofo discute sobre o que seria do mundo diante de uma sociedade de consumo cada vez mais pungente que já demonstrava fadiga.

\section{Palavras-chave}

Correspondência de Vilém Flusser com José Bueno. Caso Watergate. Crise do petróleo. Falência da sociedade de consumo. Aparelho da ditadura militar no Brasil. 


\section{Introdução}

Este artigo esquadrinha as cartas ${ }^{1}$ que Flusser trocou com um de seus amigos mais próximos: o advogado José Bueno ${ }^{2}$. Tem-se nesse arquivo uma janela mais ampla para os posicionamentos políticos de Flusser, inclusive em relação à ditadura militar que havia se instaurado no Brasil a partir 1964. Por pertencer à roda de filósofos e professores do Instituto Brasileiro de Filosofia (IBF), Flusser esteve associado a um pensamento que defendia a ditadura militar. Na troca de cartas fica mais evidente a complexidade de sua postura, muito embora em seus livros e artigos, o posicionamento político de Flusser se mantinha silente, no mínimo ambíguo. Na correspondência com José Bueno, contudo, essa ambiguidade se dissipa de uma vez por todas, mostrando Flusser na defesa pela liberdade e na crítica ferrenha ao aparelho a que o Brasil estava mantido.

Assuntos cruciais para a década de 1970 eram seus tópicos de discussão. Watergate, Crise do Petróleo, a posição do Brasil na política internacional, a economia global e os efeitos degradantes da já pungente sociedade de consumo estavam entre eles. Diante desses acontecimentos, Flusser propunha a Bueno análises sobre o mundo a partir daquele momento, e seu prognóstico foi candente: "o início da agonia do ocidente" (FLUSSER, 1974c, p. 54).

Antes de prosseguir, no entanto, é relevante traçar um perfil de José Bueno. De uma forte moral católica, Bueno tinha a tendência de pensar o mundo a partir do deslocamento da centralidade da fé cristã na construção de certos valores coletivos. Era remanescente de um Brasil rural e religioso, que já na década de 1970 não encontrava centralidade na vida política. Vivia em um Brasil crescentemente urbano, em uma São Paulo crescentemente industrial e consumista. Em Bodenlos, Flusser (2007a) expressa esse deslocamento:

A decadência da realidade é vivenciada por José como morte de Deus. Tal morte se manifesta em vários níveis. A nível religioso, se manifesta como indiferença tolerante perante todas religiões estabelecidas, e como saudade da própria religião perdida. A nível epistemológico, isto se manifesta como desilusão com todo tipo de conhecimento, e como

\footnotetext{
1 Toda essa documentação está disponível no Arquivo Flusser São Paulo, também acessível via arquivo digital para pesquisadores de todo o mundo. A correspondência selecionada, porém, é apenas uma fração da relação missivista entre Flusser e Bueno disponível no Arquivo, que compreende, ao todo, cartas trocadas desde 1971 até 1990.

2 José Bueno (1918-2001) era um dos amigos mais próximos Vilém Flusser. Bueno não era um filósofo nem lecionava no Instituto Brasileiro de Filosofia (IBF), mas ele e Flusser tinham amigos em comum no IBF, como Milton Vargas. Advogado e colecionador de arte, José Bueno tinha abertura em círculos de artistas e também matinha amizade e admiração por Mira Schendel, por quem Flusser também tinha apreço. A correspondência entre Bueno e Flusser, disponível no Arquivo Vilém Flusser São Paulo, se inicia em 1971 e se intensifica a partir de 1972, quando Flusser passa a morar na Europa, mantendo-se até 1990, um ano antes de seu falecimento. Todas essas informações pudemos retirar do conjunto de cartas trocadas, visto que não há informações biográficas de Bueno publicadas de outras formas.
} 
interesse distanciado e irônico por todo progresso da ciência e da tecnologia. [...] A nível de práxis, se manifesta como um deixar se levar, como um agir praticamente automático, como imobilismo, e como tentativa de evitar toda decisão e mudança. A nível de vivência, isto se manifesta como depressão e enfado. Em suma: a morte de Deus significa a perda de todo sentido. (FLUSSER, 2007a, p. 166).

À luz da correspondência, não é ousado afirmar que o escrito de Flusser (2007a) sobre Bueno em Bodenlos revela uma frustração. Ocorre que Flusser tentou, mas não conseguiu levar Bueno a incorporar um novo mundo. Um dos hiatos na correspondência se deu depois que Bueno visita Flusser na Europa, e os dois tiveram uma discussão que não é detalhada na carta. José escreveu que preferiu não trocar cartas por o diálogo entre os dois tê-lo levado "[...] a rever muitas de minhas posições como também e sobretudo a repensar nossas relações e dissenções [...]" (BUENO, 1975, p. 66). Mas quando os dois discordaram em relação às eleições ao legislativo no Brasil no auge da ditadura militar, como veremos mais adiante, Flusser respondeu irritado em carta de 21 de janeiro de 1975: "Você diz que está revendo tuas posições, mas a carta revela o contrário: estás recaindo nas antigas. A tua viagem não te concedeu aberturas: pelo contrário, re-encerrou-te. ” (FLUSSER, 1975, p. 70).

\section{Groupes Prospectif: a crise do petróleo e a futurologia}

Entre os dias 10 e 17 de janeiro de 1974, Flusser esteve em Paris, onde comeu ostras e teve "crise de estômago violenta", conforme contou a José Bueno em carta de 18 de fevereiro daquele mesmo ano (FLUSSER, 1974b). De Paris viajou para Nova York, onde se dedicou a uma intensa agenda, entre entrevistas, mesas redondas e palestras. No dia 6 de fevereiro, ainda nos Estados Unidos, na cidade de Buffalo, Flusser participou de um curioso debate sobre futurologia em que, segundo ele, na mesma carta, estiveram sociólogos, musicólogos, filósofos, biólogos, dentre outros representantes dos diferentes campos da ciência (FLUSSER, 1974b). Em seguida, o filósofo faz ao amigo uma descrição de Nova York: "Feiura, miséria, brutalidade. Nova York está sendo abandonada aos negros e portoriquenhos." (FLUSSER, 1974b, p. 45) Ele continua:

Vida pop. Grandiosidade. Domínio judeu sobre ciência, arte, media. Liberdade de inebriante. Produtividade explosiva. América como líder científico, artístico, tecnológico, espiritual do mundo. Sociedade em decomposição: será revolução ou decadência? Aventura, imaginação, pioneirismo, com pessimismo, cinismo, oportunismo. Senso de responsabilidade universal, e medo um do outro. Natureza e clima terrível, e as pessoas muito mais modestas que na Europa, (para não falar na 
burguesia brasileira). Concorrência impiedosa e senso social agudo. [...]Politização total. Crise econômica e de petróleo. Greves. Watergate. Sexo como pornografia e arma política. The Exorcist. Mohamad Ali. Crimes. E parques cheios de crianças. Raças como elementos de jogo. Em suma: Nova York ainda e sempre o coração do mundo. Fascínio perigoso. E força de assimilação irresistível. Estando lá, a gente é automaticamente americana, venha de onde queira. (FLUSSER, 1974b, p. 45)

Flusser desenhou com suas palavras um cenário cheio de contradições. Nova York, coração do mundo, assim o é não pelas suas virtudes, mas pelos sinais de fracasso. Nova York como ícone de um mundo em decadência. E Flusser traçou esse cenário com um comentário evidentemente preconceituoso: a cidade "abandonada" (FLUSSER, 1974b, p. 45) a negros e imigrantes. Mas até mesmo essa a declaração racista guarda certa ambiguidade. Em carta anterior, de 8 de janeiro de 1974, Flusser discutiu com Bueno sobre as "aflições do homem branco ocidental" (FLUSSER, 1974a, p. 41) e previu o fim de seu reinado: "Vejo literalmente um final de todo um mundo, o nosso." (FLUSSER, 1974a, p. 41). O que exatamente ele antevia? Seria esse fim algo positivo?

A questão fundamental da carta de 18 de fevereiro, segundo o próprio Flusser (FLUSSER, 1974b) escreveu, é esta: os Estados Unidos serão o país do futuro? Na carta, ele previu que a desigualdade entre as nações daquela época levaria ao cataclisma do capitalismo ocidental. "O aspecto regional da má distribuição da riqueza é subalterno com relação ao aspecto vertical: ou continuará o domínio da burguesia no mundo ocidental graças a América, ou a redistribuição se fará às nossas custas." (FLUSSER, 1974b, p. 46). 0 fim do mundo é o declínio da burguesia branca ocidental. Flusser não parecia ver isso com bons olhos, porque, em grande medida, isto representava o seu próprio declínio: "Não caia no erro dos xeiques. Porque nós somos os xeiques. E a liberação dos fellahin ocorrerá com a queda de nós xeiques, anterior à queda de Nixon, com seu mero enfraquecimento." (FLUSSER, 1974b, p. 46).

Já na década de 1970, os conflitos no Oriente Médio e no Magrebe assumiam centralidade nas preocupações econômicas globais. 0 petróleo já estabelecia motivações obscenas por trás dessas disputas. Foi assim na revolução de 1 de setembro de 1969, na Líbia, quando Muammar al-Gaddafi tomou o poder e estabeleceu um regime patrocinador de facções antiamericanas e antissemitas. Sua ascensão derrubou o governo do rei Idris I, que mantinha exportações de petróleo para os Estados Unidos e para a Europa. Em 1973, a Guerra do Yom Kippur acarretou como consequência uma supervalorização do preço do petróleo como represália aos países apoiadores de Israel (ALVES, 2015). 0 mundo ocidental parecia mesmo entrar em colapso. E a imagem que ficou do novo mundo que se anunciaria, 
segundo Flusser, é a de Khadafi. "Talvez o mundo se venha a desinteressar da ciência e arte, e passe a interessar-se por livrinhos vermelhos e ensinamentos de Khadafi?" (FLUSSER, 1974b, p. 46).

José Bueno havia desqualificado o interesse de Flusser pela futurologia, chamando-a de "prática cigana" (BUENO, 1974a, p. 42), em carta de 1 de fevereiro de 1974. Uma previsão futurológica, porém, havia instigado Flusser a ter essa discussão com Bueno, embora ele não tenha atribuído autoria à previsão em sua carta. Flusser tenta convencer o amigo que futurologia não trata de quiromancia, mas da construção de modelos científicos que conseguem medir em grau de probabilidade o desenvolvimento de certos acontecimentos. 0 modelo que Flusser apresenta ao amigo tem, segundo ele, 35\% de probabilidade de acerto. Vale destacar antes de expô-la: em 1972, foi publicado o relatório Limites do Crescimento, dos pesquisadores do Clube de Roma, que previa um futuro ecologicamente catastrófico e encabeçou intensas discussões sobre o clima e o meio ambiente naquela década. Essa previsão parecia fortemente influenciada por diagnósticos como o daquele relatório. Assim ele a descreve:

Parece muito provável que o nível de vida cairá brutalmente não apenas nos países ricos, mas também nos pobres (por exemplo o chumbo na atmosfera e no humus, produzido pelos automóveis americanos e europeus, diminuirá a fertilidade dos solos africanos em $40 \%$ até 1990, e isto é irreversível, porque o chumbo já está circulando na atmosfera). [...] Tais dados significam que é preciso tomar certas decisões. Quais? É isto que está sendo discutido. E isto me parece ser útil. E isto está no espírito americano (FLUSSER, 1974d, p. 46).

Meses se passam, porém, e Flusser só voltaria a escrever a Bueno em 11 de junho de 1974. O interesse pela futurologia persiste. Flusser havia acabado de voltar da província francesa de Nogent S. Marne, onde participou do chamado Groupes Prospectif, um grupo multidisciplinar que tinha por objetivo discutir projeções de futuro e propor soluções razoáveis para seus principais problemas. "Inteligência e futurologia são sinônimos: previsão inteligente ." (FLUSSER, 1974a, p. 52), defendeu Flusser. Ele destacou primeiramente a diversidade de formações dos participantes. Professor de literatura medieval. Programador de TV. Funcionário do parlamento Europeu. Funcionário do Ministère de la Qualité de Vie. Sociólogo. Flusser. Estes eram os membros de um dos três grupos separados para discutir a questão de como se desenlaçariam os próximos 18 meses da humanidade. 
A previsão contida na carta de 11 de junho, para cuja formulação Flusser auxiliou, é aqui apresentada de maneira resumida e indireta, na forma do seguinte cenário (FLUSSER, 1974a, p. 53): A Guerra do Yom Kipur produziria uma crise econômica catastrófica nos Estados Unidos e nas economias de mercado, estagnando o crescimento americano. Consequentemente, o fluxo de capital passaria a circular mais fortemente na União Soviética. Rapidamente, os membros do Conselho para Assistência Econômica Mútua, a extinta COMECON, alcançariam renda per capita de seus cidadãos semelhantes aos da economia de mercado. Por esse motivo, os países do então chamado Terceiro Mundo passariam a reorientar-se em relação à União Soviética. Em termos sociais, a desigualdade na América tenderia a corroer suas instituições, e os soviéticos se apresentariam de maneira mais estável para receber investimentos. As desigualdades no Terceiro Mundo, porém, se manteriam, e o que se alteraria seria apenas seu eixo de orientação. 0 ponto crítico dessa transformação seria quando a renda na Alemanha Oriental se igualasse a da Alemanha Ocidental. As consequências possíveis desse processo seriam, segundo Flusser: "(a) a 'finlandização' do Mercado, (b) neofascismo no Mercado (antissemitismo, regime de austeridade, de 'força', etc.) [...] " (FLUSSER, 1974a, p. 53).

Essas previsões não se concretizaram completamente, a não ser pelas consequências. Mas o próprio Flusser não demonstrava estar interessado na eficácia do cenário. 0 prognóstico que ele faz, em seguida, anunciava um processo contínuo: o começo do fim da sociedade de consumo americana.

Mas parece claro, independentemente de qualquer pessimismo deliberado, que a Terra não suportará por prazo médio a explosão demográfica, a poluição, o desenvolvimento industrial indiscriminado, e a comunicação de massa. Este o horizonte sombrio do cenário, mas apenas horizonte. (FLUSSER, 1974a, p. 54).

Logo em seguida, escreve, porém, que não permitirá "que tais preocupações ocupem o centro" de seu pensamento. Apenas que, estando na Europa, gostaria de "participar do espírito do tempo" (FLUSSER, 1974a, p. 54).

\section{0 profeta da agonia do Ocidente: a tecnologia como projeto cósmico}

Quais seriam os sinais do fim do mundo? Dois eram os eventos de preocupação central na discussão de Flusser e Bueno: o escândalo de Watergate e a crise do petróleo. Os dois, no entanto, as viam de maneiras opostas. Flusser (1974b) acreditava que esses eventos 
eram os sinais do enfraquecimento do Ocidente, e temia pelos efeitos do fim desta ordem. Já Bueno os subestimava. Sobre Watergate, em carta de 29 de agosto de 1974, Bueno recorre a moral religiosa norte-americana como forma de relativizar a crise:

É verdade que o Brasil é um país católico [...] talvez isso explique a surpresa que tivemos com a ingenuidade do povo americano de pedir do Nixon para dizer toda a verdade não mais que a verdade, quando estava envolvido em acontecimento, que lhe podia custar a cabeça. [...] Os santos da igreja seriam expulsos dos altares se pudéssemos saber o que disseram e pretenderam fazer nas crises que enfrentaram em suas vidas. [...] A história americana antiga e recente está repleta de obstruções desta natureza, que nunca escandalizariam ninguém. [...] Na verdade, como um dos típicos produtos da moral quaker, ele [Nixon] entendeu que as aparências deveriam ser mantidas até nos casos limites. Nixon é, portanto, um anacrônico mártir quaker. (BUENO, 1974b, p. 56).

Bueno aparenta divertir-se com a ingenuidade dos norte-americanos. Como se, comparado ao Brasil, esse escândalo não passasse de um rodapé na biografia de um presidente. Flusser, todavia, conforme afirmou meses antes, em 8 de janeiro daquele ano, via o acontecimento como "avalanche que ameaça varrer nosso mundo" (FLUSSER, 1974a, p. 41). Na carta, ele demonstrava especial temor com a presença de generais do exército norteamericano, como Alexander Haig, na Casa Branca. No auge da crise, o secretário de defesa James Schlesinger articulava nos bastidores para que os militares cometessem traição ao presidente caso Nixon permanecesse em sua obsessão de ficar no poder.

Sobre a crise do Petróleo, Bueno reconhecia seu impacto, mas defendia que esta não seria uma crise inédita e, portanto, logo se dissolveria. Assim Bueno escreveu em carta de 18 de dezembro de 1973:

Não é, como pretende, a primeira vez que o progresso tecnológico está se aproximando da disponibilidade dos objetos manipuláveis. Já outras civilizações tiveram seu progresso detido e, inclusive desapareceram porque o seu progresso tecnológico encontrou limite instransponível nos objetos que estavam aptas a manipular, v.g., a civilização maia que desapareceu quando esgotadas as terras que se prestavam para a cultura do seu principal alimento (o milho) [...] (BUENO, 1973b, p. 35).

Para Flusser, porém, aquela crise evidenciava o projeto tecnológico do petróleo de modo diferente aos de outrora. Conforme o filósofo escreveu em carta de 8 de janeiro de 1974, em resposta, “[...] a tecnologia atual é outra coisa: é um projeto cósmico. E tal projeto somos nós, e é 'de te fabula narratur'." (FLUSSER, 1974a, p. 41). Mas Flusser não desenvolve este projeto na ocasião daquela carta. Logo em seguida, na mesma correspondência, fez uma 
comparação de si mesmo com o profeta Jeremias. “[...] o espírito de Jeremias está em mim mais vivo " (FLUSSER, 1974a, p. 41), escreveu Flusser. Jeremias foi o profeta que predisse a queda de Jerusálem e denunciava os mal feitos dos soberanos, profetizando grande destruição e agonia, bem como a redenção dos leprosos e pobres.

Para precisar a definição de projeto cósmico da tecnologia, vamos buscar uma possível fonte de Flusser cuja obra filosófica auxilia na compreensão do que seria esta cosmologia. Ernst Cassirer (2005), ao tratar do mundo humano do espaço e do tempo, nos oferece um entendimento sobre a cosmologia humana que dialoga com o trabalho de Flusser. Ele diferencia o espaço-tempo orgânico do espaço-tempo simbólico (CASSIRER, 2005, p. 74). 0 primeiro é um espaço-tempo de ação, não ideacional, no qual os organismos estão e vivem neste instante, e são capazes de responder e se adaptar a ele de maneira instintiva. Os humanos dividem esse cosmo com os demais organismos vivos. Todavia, segundo Cassirer (2005), são os humanos também animais simbólicos, o que implica que o cosmo em que vivemos não é apenas orgânico, mas também é efeito da nossa capacidade de pensamento abstrato. Em um primeiro momento do desenvolvimento simbólico, esse espaço-tempo simbólico/abstrato ganha característica mítica. Mesmo quando sistematizado, o espaço-tempo mítico está sincronicamente preso ao sujeito, exibe características egocêntricas e antropomórficas e é enraizado no concreto e substancial (CASSIRER, 2005). Nesse espaço-tempo,

[...] a própria experiência primária está impregnada, de ponta a ponta, deste configurar de mitos e como que saturada de sua atmosfera. 0 homem só vive com as coisas na medida em que vive nestas configurações, ele abre a realidade para si mesmo e por sua vez se abre para ela, quando introduz a si próprio e o mundo neste médium dútil, no qual os dois mundos não só se tocam, mas também se interpretam. (CASSIRER, 1972, p. 24, grifo do autor).

Retomando o exemplo citado por Bueno, na mitologia maia há Chaac, o deus da chuva, representado por um guerreiro cujas lágrimas caem na terra. Por isso mesmo, tornou-se deus da agricultura e era adorado por quatro entidades diferentes (cada um representando um dos pontos cardeais). Ou seja, entre os maias, como também é notável em outros sistemas mitológicos, a agricultura e o cultivo da terra estão ligados diretamente à qualidade de uma entidade divina (CANDIDO; NUNES, 2012). Segundo Cassirer (2005), com o desenvolvimento da matemática, o espaço-tempo se desmistifica para dar espaço a um espaço-tempo simbólico que passa a ter característica geométrica. Agora, todo o conhecimento do espaço-tempo e das relações espaciais e temporais pode ser traduzido 
pela linguagem dos números, pode ser medido. Trata-se do sonho da mathesis universalis, a matemática como linguagem universal. A própria ideia de um espaço-tempo uniforme permite a concepção simbólica de uma ordem cósmica singular e sistemática, de obediência às leis do universo. Todavia, isso também permite a abstração do espaço-tempo: podemos descrevê-lo sem a concreticidade do pensamento mítico.

Podemos traçar um paralelo entre o pensamento cassireriano e o flusseriano para entender o projeto cósmico da tecnologia. Isto é porque, para Flusser, em sua escalada da abstração, o espaço-tempo nulodimensional é fruto de configurações numéricasalgorítmicas (MENEZES, 2009). 0 mundo da comunicação nulodimensional, produzida por aparelhos. Portanto, pode-se deduzir que por projeto cósmico da tecnologia faz-se uma alusão ao conceito de aparelho. Ou seja, o projeto da tecnologia é o de uma mudança de consciência, do lugar do ser-no-mundo, do mítico ao matemático. Esse argumento também é desenvolvido por Flusser em sua filosofia da caixa-preta. A tecnologia, à qual Flusser se refere na carta, se apresenta como modelo de pensamento. No trecho a seguir esse argumento se clarifica:

\begin{abstract}
Sempre se supôs que os instrumentos são modelos de pensamento. 0 homem os inventa, tendo por modelo seu próprio corpo. Esquece-se depois do modelo, 'aliena-se', e vai tomar o instrumento como modelo do mundo, de si próprio e da sociedade. Exemplo clássico dessa alienação é o século XVIII. 0 homem inventou as máquinas, tendo por modelo seu próprio corpo, depois tomou as máquinas como modelo do mundo, de si próprio e da sociedade. Mecanicismo. No século XVIII, portanto, uma filosofia da máquina teria sido a crítica de toda ciência, toda política, toda psicologia, toda arte. (FLUSSER, 1987, p. 98).
\end{abstract}

Estar no mundo do aparelho implica viver, conhecer e agir em função dele. Para o fotógrafo, significa viver, conhecer a agir em função da fotografia. Para a pessoa que depende de combustíveis fósseis, implica em viver, conhecer e agir em função do petróleo. Para o norte-americano, que vive no regime presidencialista, implica em viver, conhecer e agir em função do presidente. Para o brasileiro da década de 1970, implica em viver, conhecer e agir em função de uma tenebrosa ditadura militar. Esse é o projeto cósmico.

De mãos dadas ao conceito de aparelho está o conceito de funcionário. Como mencionado, o aparelho é descrito em Filosofia da Caixa Preta, mas é em outra obra, Da religiosidade, que o conceito é tratado para além da fotografia ou da tecnologia per se. Em Filosofia, o funcionário é definido como "pessoa que brinca com o aparelho e age em função dele" (FLUSSER, 1987, p. 5). Já o aparelho é "brinquedo que simula um tipo de pensamento" 
(FLUSSER, 1987, p. 5). "Funcionar" é, para Flusser, "permutar símbolos programados" (FLUSSER, 1987, p. 16). O funcionário então é aquele que faz um aparelho funcionar. Sem ser capaz de compreendê-lo completamente, o funcionário é aquele domina o aparelho que o torna um dominado, e obedece a suas instruções de forma desencadear o programa. Em Da religiosidade, o funcionário aparece como aquele que não compreende a finalidade do aparelho (FLUSSER, 1967). Ele escreve: "Para o funcionário, a pergunta pela finalidade do aparelho em função do qual ele funciona é uma pergunta metafísica no sentido pejorativo do termo. Carece de significado." (FLUSSER, 1967, p. 71).

Este é o fim do mundo. Os temores de Flusser com Watergate ou com a crise do petróleo não são apenas de um conservador que teme pelo fim de seus privilégios. Ao denunciar o projeto tecnológico - lê-se, aqui, também do petróleo - enquanto cósmico, ele alerta para uma sociedade de consumo que, de tão preponderante, conduziria para uma vida sem significado. E as crises mencionadas nas cartas apenas deflagraram sua falta de significado. A preocupação de Flusser não é apenas com o velho homem branco, o fim dos xeiques, mas com a falta de perspectiva da chegada de um novo homem, um que não estivesse resignado ao aparelho. Em carta de 25 de outubro de 1972, portanto anterior à crise do petróleo, Flusser (1972) faz uma crítica a ideia de "progresso" e prevê quais seriam os seus efeitos. Diante do que ele observa como "progresso inevitável", aponta quais seriam os problemas existenciais que derivariam do "aburguesamento massificador do proletariado" que tornaria quaisquer movimentos de contestação ao aparelho "meros epifenômenos inócuos e desprezíveis" (FLUSSER, 1972, p. 5). Cita, então, o destino da América Latina, enquanto periferia deste processo. Ele descreve como vê a situação:

Tal 'progresso' está aniquilando, pelo menos a curto prazo, toda esperança de um 'novo homem', isto é: de uma vida que tenha significado. Isto do ponto de vista dos que vivem em um dos quatro blocos decisivos. 0 resto da humanidade está condenado, a curto prazo, a observar tal aburguesamento maciço com inveja de fora. E o que é pior, está condenado a nem sequer poder vivenciar os terrores do aburguesamento que está invejando (Isto do ponto de vista de quem vive na América Latina, Ásia ou África). De forma que a alienação nos blocos centrais é a do homem não poder viver os verdadeiros problemas vitais, que são culturais e religiosos, não econômicos e sociais; e a alienação nas periferias é a do homem nem sequer poder constatar a própria posição no meio dos acontecimentos. (FLUSSER, 1972, p. 5). 
Anos depois desta carta, em outra troca de correspondência de 21 de janeiro de 1975, já tendo passado o pior da crise do petróleo, Flusser volta a argumentar com Bueno sobre a insustentabilidade deste projeto:

Quanto ao petróleo: continua havendo superprodução no mundo. A cartelização apenas encobre o fato. Tal cartelização fez com que enormes jazidas novas tenham sido descobertas em toda parte [...]. Mas os capitais para explorar tais jazidas não são mobilizáveis, porque há necessidades de capitais para a agricultura. 0 fato é que o petróleo não é mais considerado fonte de energia que tenha futuro. Não por causa do preço, (este voltará a cair em futuro breve). Mas por ser 'inimigo do ambiente', e por ser o automóvel transporte antieconômico e desumano. (FLUSSER, 1975a, p. 75).

As cartas com José Bueno não só oferecem uma perspectiva clara de como Flusser via seu tempo, mas também por meio de quais chaves. E sua comparação com o profeta Jeremias demonstra, aqui, não ser trivial. Tal qual o profeta, Flusser parecia estar convencido de que a sua posição era a de anunciar o destino fatal que aguardaria a humanidade caso não fosse ela capaz de se reinventar. Mas também a comparação com o profeta permite compreender como o universo da mítica religiosa exercia papel central nesse seu modo de perceber tal situação.

O funcionário do aparelho não tem acesso ao transcendente. Não tem acesso ao significado do que ele faz sob as instruções dos aparelhos - no caso, do sistema político que se tornam cada vez mais impenetráveis (FLUSSER, 1967). Em Da religiosidade, Flusser define a questão assim:

Chamarei de religiosidade a nossa capacidade para captar a dimensão sacra do mundo [...] A capacidade religiosa torna profundo o mundo, opacas as coisas (porque nunca são inteiramente explicáveis) e torna problemática a morte. [...] Essa capacidade revela o mundo e a nossa vida dentro dele como realidade significativa, isto é, como realidade que aponta para fora de si mesma. (FLUSSER, 1967, p. 12).

A religiosidade para Flusser, portanto, se dá como toda forma de abertura ao transcendente, ainda que não seja necessariamente por via das religiões tradicionais. $\mathrm{Na}$ obra, ele define a época das tecnologias como "religiosamente pobre", o que gera o " [...] desvio do ardor religioso da dimensão sacra para a profanidade chata do mundo e resulta em pseudo-religiosidades como o endeusamento do dinheiro ou do Estado." (FLUSSER, 1967, p. 13). A busca por um novo homem, portanto, é definida por uma desesperada busca por um sentido novo. Ele descreve: 
Para a Idade Antiga, a realidade se concretiza nos mitos, para a Idade Média na fé, para a Idade Moderna nos sentidos. Para nós, geração a um tempo epigônica e pioneira, a realidade é problemática e a luta por um senso de realidade é o tema de nossas vidas. [...] Estamos todos nós, Ocidentais em geral, e nós no Brasil em particular, empenhados na procura de um novo senso de realidade. (FLUSSER, 1967, p. 130).

Seria essa busca possível? A troca de cartas com Bueno está repleta de momentos em que Flusser tenta retirar o amigo de seu desengajamento. Em uma dessas ocasiões, de 7 de agosto de 1973, Flusser escreve: “Agir pressupõe dois fatores: (a) que a realidade não é como deve ser e, (b) que sabemos aproximadamente como deve ser. Se continuamos agindo, é que estamos assumindo tais dois fatores pela nossa práxis, embora os recusemos na teoria. " (FLUSSER, 1973a, p. 20). Tal como Jeremias, Flusser anunciava grande agonia. Porém, sua questão não seria tanto se o mundo iria acabar ou não, porque ele aparentemente havia acabado, mas sim o que viria depois do fim do mundo. É possível ler Flusser e compreender seu cenário profético retomando Cassirer e sua reflexão sobre o tempo simbólico. Cassirer descreve da seguinte maneira o tempo profético do Antigo Testamento:

Esses mestres religiosos não se contentavam em prever simplesmente os eventos futuros ou em se prevenir de males futuros. 0 futuro de que falavam não era um fato empírico, mas uma tarefa ética e religiosa. [...] A profecia não significa uma simples previsão; significava uma promessa. (CASSIRER, 2005, p. 94).

Os cenários dos profetas não são apenas a negação de tudo, o fim de todos os dias, mas contêm também a visualização de dias melhores. 0 engajamento de Flusser em anunciar a agonia do Ocidente em seus cenários para o futuro, em tese, não reconhecia alguma possibilidade de redenção - o que faz dele um profeta invertido. Mas sua insistência em anunciar esta agonia, em seu vivo espírito de Jeremias, revelava um compromisso: o de comunicar-se.

Assim, a comunicação assume uma centralidade em seu pensamento. Em $O$ mundo codificado, por exemplo, Vilém Flusser oferece uma definição de Comunicação:

O objetivo da comunicação humana é nos fazer esquecer desse contexto insignificante [da natureza sem significado] em que nos encontramos completamente sozinhos e incomunicáveis - ou seja, é nos fazer esquecer desse mundo em que ocupamos uma cela solitária e em que somos condenados à morte [...]. A comunicação humana é um artifício cuja intenção é nos fazer esquecer a brutal falta de sentido de uma vida condenada à morte. (FLUSSER, 2007b, p. 90). 
José Bueno não foi capaz de compreender a necessidade de comunicar a catástrofe quando acusou a futurologia do amigo de quiromancia. Há no termo "quiromancia" a raiz indo-europeia mein, da qual deriva o grego manis (a cólera legítima da vingança dos deuses) e mania (loucura, o delírio profético) (BORDELOIS, 2007, p. 47). São termos que, na Grécia, eram usados para designar os dons magníficos dados pelos deuses que o ocidente católico, representado por Bueno, trataram de suprimir.

\title{
4 Não construir Brasília, mas destruir Nova York: a ditadura militar como aparelho
}

Conforme mencionado, o Flusser daquele período acreditava que o Brasil estava na periferia das decisões globais. Como tem-se buscado demonstrar pelas cartas, Flusser parecia compreender que o mundo do progresso, àquela altura representado por automóveis e petróleo, estava fadado ao fracasso. Mas o Brasil - ou a América Latina - não estava empenhado em adaptar-se aos novos ventos que viriam: um mundo sem automóveis ou sem petróleo, por exemplo.

Em Fenomenologia do brasileiro, esse problema aparece de maneira mais evidente:

\begin{abstract}
A ideologia imagina o homem como ente na natureza, mas não da natureza. [...] Tal antropologia funcionou na sua prática maravilhosamente bem durante milênios (graças à ciência e à tecnologia), e tal funcionamento encobria o seu caráter ideológico e abstrato. Mas agora se torna óbvio tratar-se de imagem do homem que encobre sua realidade concreta [...]. Tal desprezo do concreto se vinga (como dizemos, atualmente, com a sabedoria do profeta invertido) e ameaça a humanidade com a catástrofe do abismo entre as várias dicotomias. (FLUSSER, 1998, p. 169, grifo).
\end{abstract}

Em Fenomenologia, porém, Flusser entendia que a ideologia do progresso, conforme apresentada acima, não é, no Brasil, “ [...] substrato de todo pensar, esperar, sonhar e agir, como na Europa [...]" (FLUSSER, 1998, p. 168), e por isso mesmo seria possível uma atitude brasileira diferente da europeia, ou mesmo da norte-americana. Mas na mesma obra, Flusser denuncia que o Brasil não teria alcançado "o nível que torna o delírio evidente" (FLUSSER, 1998, p. 172). Nas cartas com Bueno, a maneira como Flusser percebia a submissão ao aparelho no Brasil, em sua época, fica mais evidente.

Em carta de 14 de novembro de 1973, Bueno contou ao amigo sobre uma viagem de carro que fez e relatou ter causado surpresa ver toda a região do interior de São Paulo maciçamente cultivada. Ele disse: "A mecanização e a adubação racional permitiram o 
cultivo de terras que sempre foram consideradas impróprias para a nossa agricultura que se baseou sempre na exploração das terras virgens [...] (BUENO, 1973a, p. 27). Também se surpreendeu com Brasília: "Planejadas por ideólogo da escola de Le Corbusier e com outras influências difíceis de serem discernidas, Brasília propõe um novo relacionamento entre seus habitantes [...]" (BUENO, 1973a, p. 27). Para Bueno, Brasília permitia uma vida em comunidade que as grandes cidades não ofereciam. Nas grandes cidades, " [...] as pessoas se encontram apenas nos locais de trabalho e, após terminado, voltam para as suas tocas, onde esperam o outro dia, para recomeçar tudo de novo." (BUENO, 1973a, p. 27). Por isso, para José Bueno, "as relações entre vizinhos [nas grandes cidades] foram reduzidas a um mínimo" (BUENO, 1973a, p. 27). Ele conta como as pessoas com quem conversou por lá disseram que Brasília era "ideal" e que "não sentem falta de nada" (BUENO, 1973a, p. 28). A esta anedota, Bueno recebe resposta de Flusser de 27 de novembro de 1973:

Na medida que o automóvel vai sendo superado, cidades-automóvel como Brasília estarão condenadas. São fenômenos da primeira metade do século, e ninguém chorará seu desaparecimento. Mas haverá problemas com a dissolução das cidades do tipo Paris e New York que ainda não põem nem sequer imaginados. Isto é o que interessa: destruir NY, não construir Brasílias e Calcutás! (FLUSSER, 1973b, p. 30).

Brasília, agora vista como centro político, seria novamente tópico de conversa entre os dois em uma troca de correspondências que se inicia em 11 de novembro de 1974. Na ocasião, José Bueno dividiu com Flusser sobre os eventos das eleições ao Legislativo naquele ano, durante o auge da ditadura militar. Relata que o então MDB ensaiava uma reação aos militares na tentativa de retomar o regime político pré-1964, porém o partido havia recuado na tentativa. Bueno, então, opinou:

Todavia, [MDB] mudou sua orientação logo que a ARENA contra-atacou usando uma arma infalível do arsenal político brasileiro: o risco da desordem, implícito na volta ao regime anterior à revolução. A desordem por aqui é um fantasma que sempre esfriou os ânimos mais exacerbados e conduz nossos políticos a composições quase que impossíveis. Não sei bem por que o brasileiro, mesmo aquele que nada tem a perder, teme tanto a desordem. (BUENO, 1974c, p. 63).

Flusser, então, respondeu em carta de 22 de novembro, em que faz a seguinte leitura do evento:

(a) a oposição articulou livremente alguns argumentos radicais contra o regime, embora não tenha articulado os argumentos de base. (b) a oposição utilizou tal liberdade de expressão com grande 
irresponsabilidade. A primeira conclusão implica que existe ampla liberdade de expressão, embora não irrestrita. A segunda implica que tal liberdade é abusada, porque os que a têm sabem que não assumirão a responsabilidade pelas suas convicções em futuro previsível. (FLUSSER, 1974d, p. 64).

Flusser criticava o fato de haver eleições, sabendo que elas não teriam efeito decisivo sobre os destinos da nação, já que o executivo continuava atuando com quase total independência do legislativo. Para Flusser, aquelas eleições eram mero " [...] ritual destinado a criar a impressão e democracia burguesa tanto no interior do país quanto fora. Aliás, a própria manutenção do legislativo se enquadra dentro da explicação proposta." (FLUSSER, 1974d, p. 64). Logo em seguida, claramente define a ditadura militar brasileira enquanto aparelho:

O material que você me mandou prova que as eleições tinham função muito mais concreta. Serviam de válvula de escape a forças que se acumulam durante o processo de administração sem feedback. Tais forças são potencialmente perigosas para o estabelecimento. São, com efeito, responsáveis pela curta duração de administrações fechadas (fortes) no século 20. Com a válvula de escape tais forças se volatizam, e reforçam o aparelho. A oposição funcionou, pois, como parte integrante do aparelho, e provavelmente muito mais eficiente que não importa que o instrumento de repressão de tais forças. [...] Os que se engajaram na propaganda da oposição o fizeram conscientes das limitações impostas pelas regras do jogo. Mas duvido que estivessem também conscientes da sua função dentro do aparelho. Porque admitir isto seria admitir uma má fé muito pouco provável. A situação existencial dos oposicionistas me parece ter sido esta: dada a "abertura" concedida pelo aparelho, era racional e eticamente imperativo aproveitar a brecha. Não se davam conta que a brecha era válvula de escape. Sentiam-se livres dentro da abertura, e dentro dos limites da abertura, quando na realidade era exatamente o oposto: teriam sido mais livres se não tivessem funcionado dentro da brecha. 0 que vivenciavam como sendo liberdade era na realidade uma função que o aparelho lhes impunha. E isto é para mim o aspecto fascinante do problema. A sensação subjetiva da liberdade pode esconder um condicionamento objetivo. Não se trata da dialética hegeliana da liberdade: sou subjetivamente absolutamente livre, e sou objetivamente absolutamente determinado. Trata-se de outra coisa: o aparelho me concede liberdade subjetiva a fim de poder melhor determinar-me. Com efeito: sou determinado na medida na qual permito que tal liberdade subjetiva me seja concedida. [...] Em outros termos o problema é este: existem engajamentos existencialmente honestos que são objetivamente autodestrutivos, porque funcionam em função daquilo contra o qual o engajamento se dirige subjetivamente. E o sintoma de tal tipo de engajamento é a irresponsabilidade, fruto da consciência confusa de tal contradição interna. (FLUSSER, 1974d, p. 64-65).

Bueno respondeu em 3 de janeiro de 1975 para avisá-lo de que não concorda com sua ideia de liberdade concedida: "O seu pensamento político é tipicamente pré-Maquiavel. 
A liberdade, que você prudentemente não define, emerge do seu raciocínio como um bem transcendente, conquistável através de rituais mágicos que você não menciona." (BUENO, 1975, p. 66). Bueno se dedica a uma longa exposição de como, após Maquiavel, entende-se a liberdade, bem como os demais direitos políticos, como consequência da acomodação de diversos interesses. Ele argumenta que "O conceito de liberdade é mercurial e por isto vem sendo utilizado por uns e por outros conforme sua conveniência[...]" (BUENO, 1975, p. 68).

A próxima carta é justamente aquela em Flusser confrontou Bueno, mencionada ao início deste artigo. Em 21 de janeiro de 1975, Flusser coloca-se claramente contra a ditadura militar:

Liberdade política não precisa de tanta elaboração e sabedoria que você gasta nela, e nem precisa ser pesquisada até Machiavello. Está na cara e é insofismável. Quem a cerca de tanta saliva é que sabe que está defendendo posição indefensável. A liberdade política é um clima que se respira ou não respira, e não deixa margem a dúvida. É a situação na qual a gente diz o que bem entende sem ter medo, na qual a gente não tem medo de farda, na qual a gente não "respeita" funcionários, em suma: na qual a gente assume dono da coisa pública, e não receptor dos benefícios que a coisa pública generosamente confere (FLUSSER, 1975a, p. 70).

Em seguida, Flusser oferece ao amigo a sua definição de liberdade, contra o aparelho:

Existencialmente, ela é a convicção que faço o que quero, embora saiba que há motivos para meu ato e para a minha vontade. Moralmente, ela é a aceitação da responsabilidade apenas pelos atos existencialmente livres. Politicamente ela é uma situação na qual nenhum grupo, seja majoritário ou minoritário, pode impor-se sobre os demais grupos sem que estes tenham tido a oportunidade de manifestar-se publicamente seus pontos de vista, e sem que exista mecanismo que possibilite a tais grupos a impor-se no futuro. Economicamente, ela é a situação na qual há mecanismos que permitem a todos (individualmente e em associações) negociar seu trabalho, na qual a todos é garantido um mínimo de bens de consumo. Socialmente ela é a situação na qual o jogo das tensões sociais dispõe de mecanismo adequado. Culturalmente ela é a situação na qual não há censura. Em todas estas camadas (e em outras), liberdade é situação de limite, jamais alcançável, mas infinitamente aproximável. De modo que não se pode dizer jamais que tal ou qual situação seja livre, mas que é mais ou menos livre que a outra. Assim é possível dizer que na Suíça há mais liberdade que na Arábia Saudita, e quem quer negá-lo é obscurantista. (FLUSSER, 1975a, p. 70). 


\section{A melhor estratégia para prospectivas é o pessimismo}

Como buscou-se demonstrar, as cartas de Flusser estão repletas de suas visões para o futuro. Sabemos que a preocupação com a futurologia é importante para a obra flusseriana. Lembramos que um de seus livros inacabados é justamente Vom Subjekt zum Projekt (Do subjeto ao projeto). Nas cartas, é possível rastrear a crise do petróleo como sendo um dos momentos de sua biografia em que este interesse se tornou marcante. As cartas também auxiliam a desvendar qual a metodologia que Flusser usava para desenhar esses cenários. Nisso, a participação no Groupes Prospectif parece ter sido fundamental. Na carta de 11 de junho de 1974, o próprio Flusser descreve a metodologia do grupo, que ele acompanhava com interesse. E aqui, vale reproduzi-la resumidamente (FLUSSER, 1974c): (1) Desenhar os personagens de um cenário; (2) Pensar em uma projeção a partir de uma catástrofe iniciadora de uma transformação; (3) Propor em qual seria a mudança fundamental neste cenário a partir da catástrofe; (4) Propor uma consequência a esta mudança; (5) Identificar um problema central específico, ou ponto crítico que sinaliza a virada da situação comum para a situação alterada. Foi assim o passo-a-passo para a previsão sobre a reorientação da economia global diante da crise do petróleo mencionada por Flusser na mesma carta - a qual citamos anteriormente. Outro elemento importante para a construção desses cenários: "a melhor estratégia para prospectivas é o pessimismo" (FLUSSER, 1974c, p. 52).

Mas seria um exagero deduzir que Flusser se consideraria um futurólogo. Mesmo tentar descrever metodologicamente seu modo de projetar cenários parece reduzir a intenção por trás de suas previsões. Em Fenomenologia, Flusser chega a descrever a futurologia como modo de "manipular o futuro" (FLUSSER, 1998, p. 171). Isso porque o futurólogo busca compreender as regras da realidade como regra de um jogo e tenta esquadrinhar todos os lances possíveis. Se um lance não previsto ocorre, a tentativa da futurologia é a de mudar as regras, readequá-las. A tentativa da futurologia é a de acertar um futuro que fosse histórico. Não era preocupação de Flusser acertar em suas previsões. Era um profeta invertido dedicado à crítica à era do aparelho.

Mais do que uma tentativa de reduzi-lo a procedimentos metodológicos, fica também ainda mais claro como o pensamento flusseriano é movido por catástrofes. Neste ponto, recordamos o texto de Baitello Junior (2005) Vilém Flusser e a terceira catástrofe do homem ou as dores do espaço, a fotografia e o vento, em que o autor comenta algumas das conferências de Vilém Flusser nos Seminários Internacionais do Celeiro. Nessas 
conferências, Flusser descreve as três catástrofes da humanidade. A primeira, a hominização, trazida pelo uso das ferramentas de pedra; a segunda, a civilização, criada pela sedentarização; e a terceira, ainda em curso e sem nome (BAITELLO, 2005).

\begin{abstract}
Na primeira, o homem desenvolve ferramentas e persegue a caça, é nômade como a caça e como o vento; ao andar (como o vento) toca e apreende o mundo. Na segunda, constrói casas, doméstica e cria sua caça; começa a possuir coisas e, como possui, torna-se fixo na terra, não mais pode andar para apreender o mundo; cria as imagens tradicionais e a escrita que substituem o mundo e os seus percursos (e somente apreende o mundo com sua mediação). Na terceira, sua casa fica inabitável, porque por todos os seus buracos entra o vento da informação (com suas imagens técnicas, transmitidas pelas tomadas de eletricidade) (BAITELLO JR. 2005).
\end{abstract}

À luz desta correspondência, fica mais clara a dimensão política da terceira catástrofe. Esta catástrofe, ainda sem nome, é decorrente do projeto cosmológico da tecnologia, do petróleo ou da ditadura. A tarefa é a de não se integrar a este projeto. Em carta de 24 de março de 1975, Flusser retorna ao amigo com um conselho: "Quem se integra se perde, e quem se 'engaja' se encontra, e para engajar-se é preciso primeiro des-integrarse para depois re-integrar-se. Os profetas devem sair para o deserto e a montanha, para poderem voltar. " (FLUSSER, 1975b, p. 72).

\title{
Referências
}

ALVES, Waldon Volpicelli. Uma breve história das crises econômicas. São Paulo: Simplíssimo, 2015.

BAITELLO JUNIOR, Norval. Vilém Flusser e a terceira catástrofe do homem ou as dores do espaço, a fotografia e o vento. In: KONDO, Kojin.; SUGA, Keijiro. (org.). How to talk to photography. Tokyo: Kokushokankokai, 2005, p. 87, a. 94 BORDELOIS, Ivonne. Etimologia das paixões. Rio de Janeiro: Odisséia Editorial, 2007.

BUENO, José. Correspondência a Vilém Flusser: Cor_17_6-BUENO_3125_JOSE BUENO 1971-1990 1 of 4. [S. l.]: Arquivo Vilém Flusser São Paulo, 14 nov. 1973a. p. 26-29.

BUENO, José. Correspondência a Vilém Flusser: Cor_17_6-BUENO_3125_JOSE BUENO 1971-1990 1 of 4. [S. l.]: Arquivo Vilém Flusser São Paulo, 18 dez. 1973b. p. 32-35.

BUENO, José. Correspondência a Vilém Flusser: Cor_17_6-BUENO_3125_JOSE BUENO 1971-1990 1 of 4. [S. l.]: Arquivo Vilém Flusser São Paulo, 1 de fev. 1974a. p. 42-44.

BUENO, José. Correspondência a Vilém Flusser: Cor_17_6-BUENO_3125_JOSE BUENO 1971-1990 1 of 4. [S. l.]: Arquivo Vilém Flusser São Paulo, 29 ago. 1974b. p. 55-60. 
BUENO, José. Correspondência a Vilém Flusser: Cor_17_6-BUENO_3125_JOSE BUENO 1971-1990 1 of 4. [S. l.]: Arquivo Vilém Flusser São Paulo, 11 nov. 1974c. p. 62-63.

BUENO, José. Correspondência a Vilém Flusser: Cor_17_6-BUENO_3125_JOSE BUENO 1971-1990 1 of 4. [S. l.]: Arquivo Vilém Flusser São Paulo, 3 jan. 1975. p. 66-69.

CANDIDO, Daniel Henrique. NUNES, Lucí Hidalho. Mitologia e Climatologia: Um estudo das divindades relacionadas à ocorrência do tempo severo. Revista Brasileira de Climatologia, 2012, A,8, V. 11, p. 42-55.

CASSIRER, Ersnt. Linguagem e mito: uma contribuição ao problema dos nomes dos deuses. São Paulo: Perspectiva, 1972.

CASSIRER, Ersnt. Ensaio sobre o homem: introdução a uma filosofia da cultura humana. São Paulo: Martins Fontes, 2005.

FLUSSER, Vilém. Da religiosidade. São Paulo: Cec, 1967.

FLUSSER, Vilém. Filosofia da caixa preta: ensaios para uma futura filosofia da fotografia. São Paulo: HUCITEC, 1987.

FLUSSER, Vilém. Fenomenologia do brasileiro: em busca de um novo homem. Rio de Janeiro: EdUERJ, 1998.

FLUSSER, Vilém. Bodenlos: uma autobiografia filosófica. São Paulo: Annablume, 2007a.

FLUSSER, Vilém. 0 mundo codificado: por uma filosofia do design e da comunicação. São Paulo: Cosac Naify, 2007b.

FLUSSER, Vilém. Correspondência a José Bueno: Cor_17_6-BUENO_3125_JOSE BUENO 1971-1990 1 of 4. [S. l.]: Arquivo Vilém Flusser São Paulo, 25 out. 1972. p. 4.

FLUSSER, Vilém. Correspondência a José Bueno: Cor_10_06-Cor_17_6-BUENO_3125_JOSE BUENO 1971-1990 1 of 4. [S. l.]: Arquivo Vilém Flusser São Paulo, 7 ago. 1973a. p. 20-21.

FLUSSER, Vilém. Correspondência a José Bueno: Cor_17_6-BUENO_3125_JOSE BUENO 1971-1990 1 of 4. [S. l.]: Arquivo Vilém Flusser São Paulo, 27 nov. 1973b. p. 30-31.

FLUSSER, Vilém. Correspondência a José Bueno: Cor_17_6-BUENO_3125_JOSE BUENO 1971-1990 1 of 4. [S. l.]: Arquivo Vilém Flusser São Paulo, 8 jan. 1974a. p. 41.

FLUSSER, Vilém. Correspondência a José Bueno: Cor_17_6-BUENO_3125_JOSE BUENO 1971-1990 1 of 4. [S. l.]: Arquivo Vilém Flusser São Paulo, 18 fev. 1974b. p. 45-46.

FLUSSER, Vilém. Correspondência a José Bueno: Cor_17_6-BUENO_3125_JOSE BUENO 1971-1990 1 of 4. [S. l.]: Arquivo Vilém Flusser São Paulo, 11 jun. 1974c. p. 52-54.

FLUSSER, Vilém. Correspondência a José Bueno: Cor_17_6-BUENO_3125_JOSE BUENO 1971-1990 1 of 4. [S. l.]: Arquivo Vilém Flusser São Paulo, 22 nov. 1974d. p. 64-65. 
FLUSSER, Vilém. Correspondência a José Bueno: Cor_17_6-BUENO_3125_JOSE BUENO 1971-1990 1 of 4. [S. l.]: Arquivo Vilém Flusser São Paulo, 21 jan. 1975a. p. 70-72.

FLUSSER, Vilém. Correspondência a José Bueno: Cor_17_6-BUENO_3125_JOSE BUENO 1971-1990 1 of 4. [S. l.]: Arquivo Vilém Flusser São Paulo, 24 mar. 1975b. p. 75.

MENEZES, José Eugenio de Oliveira. Comunicação, espaço e tempo: Vilém Flusser e os processos de vinculação. Comunicação, Mídia e Consumo, São Paulo, v. 6, n. 15, p. 165182, 2009.

\title{
Flusser, the inverted prophet: the criticism of consumer society and the apparatus of the military dictatorship in correspondence between Vilém Flusser and José Bueno
}

\begin{abstract}
This article selects and analyzes letters exchanged between Vilém Flusser and José Bueno, preserved in the Vilém Flusser São Paulo Archive. The research focused on reading the correspondence exchanged from May 29, 1971 to July 10, 1975 which corresponds to 30 letters, of which 15 are directly cited in this article. It was understood that the selected letters begin and conclude a certain thematic axis discussed among them, precisely about economics and international politics and the situation of Brazil in the global scenario of the time. Through research in this archive, some modulations were discovered on how Flusser discussed events that were contemporary with him, such as the 1973 oil crisis, the Watergate case and especially the Brazilian military dictatorship. The letters also demonstrate Flusser's interest in emerging futurology, in moments when the philosopher discusses what would become of the world in the face of an increasingly poignant consumer society that was already showing fatigue.
\end{abstract}

\section{Keywords}

Correspondence between Vilém Flusser and José Bueno. Watergate case. Oil crisis. Collapse of the consumer society. Apparatus of the military dictatorship in Brazil.

Recebido em 30/04/2020

Aceito em 23/07/2020 